\title{
The Opinions of Patients Diagnosed Diabetes on Medical Nutrition Therapy: A Phenomenological Study
}

\author{
Leyla Muslu ${ }^{1^{*}}$ (D), Melek Ardahan ${ }^{2}$ (i) and Ilhan Gunbayi3 (iD \\ ${ }^{1}$ Public Health Nursing, Faculty of Nursing, Akdeniz University, Turkey \\ ${ }^{2}$ Management in Nursing, Faculty of Health Sciences, Izmir Katip Celebi University, Turkey \\ ${ }^{3}$ Educational Management, Faculty of Education, Akdeniz University, Turkey
}

*Corresponding author: Dr. Leyla Muslu, Public Health Nursing, Faculty of Nursing, Akdeniz University, Dumlupinar Bulvari, Kampus, Konyaalti, Antalya, 07058, Turkey, Tel: +9053-6948-8003, Fax: 0242-226-6924

\begin{abstract}
Background: For patients with type 2 diabetes mellitus, medical nutrition therapy is one of the most essential components of a healthy life. The aim of this study was to investigate participants' perceptions of the process of medical nutrition therapy.

Material and methods: In this study, a qualitative phenomenological approach was adopted in order to explore in depth the experiences of patients with type 2 diabetes mellitus during the medical nutrition therapy process, which is the most important component of diabetes treatment. This study was conducted in the endocrine and metabolism outpatient clinic of the state university hospital. A qualitative phenomenological study design using Colaizzi's (1978) strategy of descriptive phenomenological data analysis was done in order to explore the subjective perceptions of these patients on medical nutrition therapy. Face-to-face interviews were conducted with 10 participants, using semi-structured open-ended questions. In this way, themes were determined from the data about the medical nutrition therapy process.

Results: The results were collected under three main themes with 23 subcategories: Participants' views on the medical nutrition therapy process, the obstacles they experienced and how they overcame and how they reached medical nutrition therapy. The sub-theme about medical nutrition therapy barriers of social pressure was the first in rank. Participants also stated the self-efficiency, importance of balanced dieting instead of restrictions in achieving medical nutrition therapy and the importance of social support.

Conclusions: According to the results of this study, the process of adaptation to medical nutrition therapy should be arranged by taking into account the perspectives, individual preferences and cultural values of patients with type 2 diabetes mellitus. The treatment process can be successful if these patients are integrated into their lifestyle.
\end{abstract}

\author{
Keywords \\ Diabetes mellitus, Medical nutrition therapy, Perception, \\ Opinion
}

\section{Introduction}

Diabetes is an important public health issue that has progressively been increasing the prevalence all over the world. In $21^{\text {st }}$ century, the diabetes has started being observed in earlier ages due to adverse changes in lifestyles such as sedentary lifestyle, unhealthy nourishment based on fast food [1,2].

All over the World the number of individuals diagnosed diabetes mellitus has reached to 463 million people [1]. According to The Prospective Urban Rural Epidemiology (PURE) study it is also stated that the prevalence of diabetes in Turkish adult population has reached 21 percent [3].

Medical nutrition therapy (MNT) is a term defined as an optimal coordination of getting calorie as well as the other aspects used in the treatment of diabetes mellitus [4]. For many individuals with diabetes, the most challenging part of the treatment plan is determining what to eat and following a meal plan. Two basic dimensions of MNT include dietary quality and energy restriction. Strategies directed at each dimension can improve glycemic control [5]. Most of the individuals diagnosed type 2 diabetes mellitus (T2DM) have their own targets such as losing weight, medical nutrition therapy and the bal-

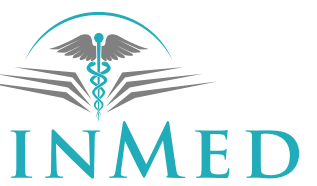

INTERNATIONAL LIBRARY

Citation: Muslu L, Ardahan M, Gunbayi I (2021) The Opinions of Patients Diagnosed Diabetes on Medical Nutrition Therapy: A Phenomenological Study. Int Arch Nurs Health Care 7:159. doi. org/10.23937/2469-5823/1510159

Accepted: May 18, 2021: Published: May 20, 2021

Copyright: (C) 2021 Muslu L, et al. This is an open-access article distributed under the terms of the Creative Commons Attribution License, which permits unrestricted use, distribution, and reproduction in any medium, provided the original author and source are credited. 
ance in the level of blood glucose to reach [4]. Although those problems come up with difficulties in adaptation to the changes in nutrition and the way to eat, the factors affecting this process have not been known in detail, yet [5]. In order to enable individuals diagnosed T2DM to participate in their own self-care programs, certain strategies should be put into action [6]. The American Diabetes Association (ADA) and the European Foundation for Diabetes Studies (EFSD) recommend patient-centered approaches to diabetes management $[4,7]$. EFSD recommendations focus on lifestyle management and diabetes self-management education and support [7]. Studies suggest that MNT should focus on patient-centered care $[8,9]$. Nurses who care individuals diagnosed T2DM should communicate with them effectively in order to increase their health quality, enable them live with the disease and survive healthy.

MNT are essential components of diabetes management. For many people with diabetes, the hardest part of the treatment plan is determining what to eat. The ADA recognizes the integral role of MNT in general diabetes management and recommends that each individual with diabetes should actively participate in self-management, education and treatment planning with their healthcare provider [5]. As a result of understanding the MNT process of individuals, the obstacles they experience in this process and how they cope with these obstacles, it is essential that the members of the healthcare team should support T2DM patients in the most vital component of their treatment.

The aim of this study was to understand what barriers participants diagnosed T2DM experienced and how they overcame those barriers in the process of medical nutrition therapy. Thus, the following questions were answered:

1. What were the opinions of participants diagnosed T2DM on medical nutrition therapy process?

2. What were the barriers participants diagnosed T2DM experienced in medical nutrition therapy process?

3. How did participants diagnosed T2DM overcome the barriers they experienced in achieve medical nutrition therapy?

\section{Methods}

\section{Model of the study}

In this study phenomenological approach based on hermeneutic interest [10] and interpretive paradigm focusing on participants' inner and subjective experiences [11] was used. The major concern of phenomenological study is to understand "how the everyday, subjective and inter-subjective world is constituted" from the participants' perspective [12]. Thus, phenomenological study focuses on descriptions of what people have experienced and how they experienced what they experienced [13]. In this study, data obtained through in-depth interviews focused on the lived experiences of T2DM patients with MNT to understand to the essence of what experienced. Additionally, "the phenomenological inquiry is particularly appropriate to address meanings and perspectives of research participants. The major concern of phenomenological analysis is to understand "how the everyday, subjective and inter-subjective world is constituted" from the participants' perspective" [14].

Phenomenological research is a design driven by the interpretive paradigm. It is the way that human experience and events are perceived as they appear to consciousness. The focus is on people perceiving the world - perceiving 'things when they arise'. Various processes need to be carried out to define the world as it seems to people [15]. The consolidated criteria for reporting qualitative research (COREQ) checklist was used for reporting the study [16].

\section{Place of the study and study group}

The population of research comprised of individuals who applied to Endocrinology and Metabolism Polyclinic in Akdeniz University Hospital in Antalya in Turkey during March and April in 2016 and were diagnosed with T2DM. The sampling of research involved a total of ten volunteer participants selected through purposive sampling method with criterion technique. This sampling continues until the researcher identifies that data saturation has occurred. During selection of participants, criteria such as their all having oral antidiabetic therapy (OAD), their being received diagnosis in last six months and their being absence of more than one co morbid/chronic disease were considered.

\section{Data Collection}

Data were collected by the researcher via semi-structured interview forms. All of the interviews were done in a separate room and tape-recorded after participants agreed and signed the consent form. Interviews took approximately 30-45 minutes. On the day when interviews were done, tape recordings were analyzed by giving each participant a code number. The level of data saturation was determined by the main researcher and by another independent researcher in a process carried out in parallel with data collection.

Written permission from the hospital was obtained, and ethical approval was taken from Clinical Trials Ethics Committee (Approval no: KAEK-206). Participation in the study was conducted on a volunteer basis and written consent was obtained from all participants. During analysis of interviews codes were used instead of real names. Informed consent form was obtained from the participants and the study was performed according to the Declaration of Helsinki Principles.

\section{Data Analysis}

The transcripts from interviews recorded on the tape recorder were also double-checked by the independent 
researcher who had experience in qualitative research prior to data analysis based on Colaizzi process for phenomenological data analysis with seven steps: (1) Familiarization: Each transcript was read and re-read in order to obtain a general sense about the whole content; (2) Identifying significant statements: For each transcript, significant statements that referred to the phenomenon under study was extracted. and recorded; (3) Formulating meanings: Meanings were formulated from those significant statements; (4) Clustering themes: The formulated meanings were organized into categories, clusters of themes, and themes by bracketing of pre-suppositions in order to avoid any probable effect of prevailing theory; (5) Developing an exhaustive description: The findings of the study were integrated into an exhaustive description of the phenomenon under study; (6) Producing the fundamental structure: The fundamental structure of the phenomenon was described and (7) Seeking verification of the fundamental structure: Validation of the findings was sought from the participants in order to compare the researcher's descriptive results with their experiences $[17,18]$.
During data decoding and categorization process NVIVO-11 package program was aided. In order to ensure reliability and validity of the study, four steps were followed: (i) Data were collected from semi-structured interviews based on related literature and the data were organized categorically and chronically, reviewed repeatedly and continually coded (ii) Data were used as direct quotations from the interviews without making any comments on them, (iii) A purposive sampling method based on voluntarism was used in order to get opinions diagnosed with T2DM (iv) Data were coded by two independent researchers and Cohen's Kappa coefficient were was calculated to determine inter-rater reliability of themes coded -0.773 substantial agreementfor inner reliability and (v) Records of interviews were kept for outer reliability.

\section{Results}

\section{Characteristics of research participants}

According to participants' socio-demographic status, five of them were female, age average was $48.2 \pm 12.29$ (minimum: 25, maximum: 65) and five were graduate

Table 1: Principal participant in research.

\begin{tabular}{|l|l|l|l|l|l|l|}
\hline Code & Age & Gender & $\begin{array}{l}\text { Institution } \\
\text { Graduated }\end{array}$ & Diagnosed T2DM & BMI & Hemoglobin A1c \\
\hline P1 & 65 & Male & Primary school & 1 month ago & 24.0 & $6.9 \mathrm{mg} / \mathrm{dl}$. \\
\hline P2 & 25 & Male & University & 1 week ago & 24.0 & $6.6 \mathrm{mg} / \mathrm{dl}$. \\
\hline P3 & 55 & Female & Primary school & 1 month ago & 28.9 & $6.8 \mathrm{mg} / \mathrm{dl}$. \\
\hline P4 & 44 & Female & High school & 3 months ago & 47.6 & $7.1 \mathrm{mg} / \mathrm{dl}$. \\
\hline P5 & 46 & Female & Postgraduate & 3 months ago & 38.2 & $6.6 \mathrm{mg} / \mathrm{dl}$. \\
\hline P6 & 34 & Male & High school & 1 month ago & 30.1 & $10.2 \mathrm{mg} / \mathrm{dl}$. \\
\hline P7 & 63 & Female & High school & 1 month ago & 27.0 & $6.7 \mathrm{mg} / \mathrm{dl}$. \\
\hline P8 & 46 & Female & High school & 1 month ago & 42.9 & $7.1 \mathrm{mg} / \mathrm{dl}$. \\
\hline P9 & 55 & Male & High school & 1 month ago & 26.2 & $10.1 \mathrm{mg} / \mathrm{dl}$. \\
\hline P10 & 49 & Male & Postgraduate & 2 months ago & 24.0 & $6.6 \mathrm{mg} / \mathrm{dl}$. \\
\hline
\end{tabular}

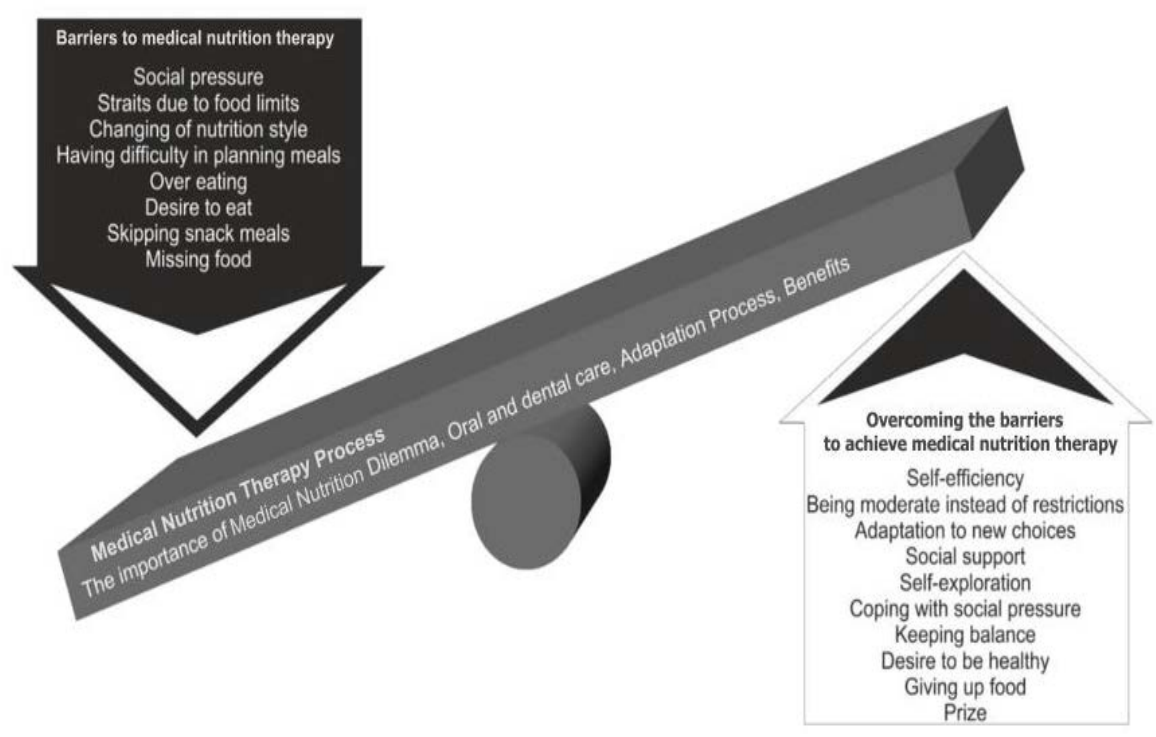

Figure 1: Medical nutrition therapy process in Type 2 Diabetes mellitus. 
of junior high school (Table 1). Participants' Hemoglobin A1c values mean was $7.45 \% \pm 1.44$ (minimum: 6.6 , maximum: 10.24) and Body Mass Index (BMI) levels mean was $31.67 \pm 8.30$ (minimum: 24 , maximum: 47.60 ). All the participants were diagnosed T2DM in six-month time, their level of Hemoglobin A1c were either 6,6 or more and they used regularly OAD.

The results based on the aim of this study were discussed under three sub-titles: the opinions of participants diagnosed T2DM on medical nutrition therapy process, barriers to medical nutrition therapy and achieving medical nutrition therapy (Figure 1 ).

The analysis resulted in creation of 23 sub-themes under three main-themes. Sub-themes of medical nutrition therapy process are shown in Table 2.

\section{Theme 1: Medical nutrition therapy process}

Participants diagnosed T2DM were asked about what they thought about medical nutrition therapy process. As it can be understood from the opinions of participants diagnosed T2DM on medical nutrition therapy process in Table 2, the theme of the importance of medical nutrition therapy is the first in rank. For example, one said:

"Nutrition is important in order to protect yourself against illness, is it? As I see from others, if you have a wound on your feet, it doesn't recover" (Participant 7).
Participants also mentioned on the theme of dilemma. For example, one said:

"It is not easy. For example, you go somewhere to eat and drink coke. You can't give up what you are used to drinking and eating. But those are the habits which can be given up. Anyway, I can succeed" (Participant 6).

\section{Theme 2: Barriers to medical nutrition therapy}

Participants' opinions about what barriers they experienced related to medical nutrition therapy were categorized under eight sub-categories. The theme of social pressure was the first in rank. For example, one said:

“...my friends always insist on by saying "I have cooked and prepared these foods. Eat, eat. Why don't you eat? It is not harmful for you". I have really difficulty in understanding such kind of pressure. If everything goes on in this way. I think I will be an asocial person" (Participant 3).

The theme of straits due to food limits was the second in rank. For example, one participant said:

"At breakfast there used to be lots of food choices but now they are limited. Psychologically you feel yourself that you are ill at the table due to limited kinds of food. You can see the food you like at the table, but you cannot eat it" (Participant 2).

Table 2: Themes and subthemes of medical nutrition therapy.

\begin{tabular}{|c|c|}
\hline Themes & Subthemes \\
\hline \multirow[t]{5}{*}{ Medical nutrition therapy process } & - The importance of nutrition \\
\hline & - Dilemma \\
\hline & - Oral and dental care \\
\hline & - $\quad$ Adaptation Process \\
\hline & - Benefits \\
\hline \multirow[t]{7}{*}{ Barriers to medical nutrition therapy } & - $\quad$ Social pressure \\
\hline & - $\quad$ Straits due to food limits \\
\hline & - $\quad$ Changing of nutrition style \\
\hline & - Having difficulty in planning meals \\
\hline & - $\quad$ Overeating \\
\hline & - $\quad$ Skipping snack meals \\
\hline & - $\quad$ Missing food \\
\hline \multirow{8}{*}{$\begin{array}{l}\text { Overcoming the barriers to achieve medical nutrition } \\
\text { therapy }\end{array}$} & - $\quad$ Self-efficiency \\
\hline & - $\quad$ Being moderate instead of restrictions \\
\hline & - $\quad$ Adaptation to new choices \\
\hline & - $\quad$ Social support \\
\hline & - Self-exploration \\
\hline & - $\quad$ Coping with social pressure \\
\hline & - $\quad$ Keeping balance \\
\hline & - $\quad$ Desire to be healthy \\
\hline
\end{tabular}




\section{Theme 3: Overcoming the barriers and achieving medical nutrition therapy}

Participants' opinions about how they overcame the barriers they experienced in medical nutrition therapy process and achieved medical nutrition therapy were categorized under 10 sub-categories. The theme of self-efficiency was the first in rank. For example, one said:

"Of course, I will take care of medical nutrition therapy in order to keep balance in my body. Self-control is of importance. I think what is important is to be patient" (Participant 1).

The theme of being moderate instead of restrictions was the second in rank. One said:

"...Why? I used to eat unhealthily and more food before. I really liked to be moderate in eating. I think, being moderate is good, for your body and also your budget" (Participant 6).

Participants also mentioned on social support. For example, one said:

"My wife supports me a lot. She bakes whole wheat bread for me at home. It is not very delicious for me, but she cooks it for me" (Participant 6).

\section{Discussion}

In this section findings related to nutrition process, barriers to medical nutrition therapy, overcoming the barriers and achieving medical nutrition therapy are discussed in comparison with the results of the studies done on medical nutrition therapy in the literature analytically.

\section{Medical nutrition therapy process}

As it can be understood from the participants' perceptions on nutrition process, the most outstanding sub-category is the importance of medical nutrition therapy. This finding is consistent with the studies in the literature indicating that medical nutrition therapy is the milestone in the treatment of T2DM and in the treatment of the individuals diagnosed T2DM medical nutrition therapy is the first step $[4,19,20]$.

The results also showed that medical nutrition therapy process took place in an adaptation period. This finding is parallel with the finding of the study done by Muchiri, et al. [21] which indicated that the change of lifestyles of the individuals diagnosed T2DM occurred in a certain period of time and changes in behavior in medical nutrition therapy were sequential. Additionally, this finding is consistent with the views stated in Roy Adaptation Model that a new behavior occurs at three levels: Integrated, compensatory, and compromised [22].

It was also understood that the most critical phase in medical nutrition therapy process was the dilemma. This finding is consistent with Arkowitz, et al. [23] views that it is possible that a dilemma should occur in the process of changing of behavior. In achieving medical nutrition therapy, the dilemma can be thought as an important phase in triggering the change in behaviors.

\section{Barriers to medical nutrition therapy}

As a result of the study, eight barriers which participants experienced in medical nutrition therapy were found out. One of sub-categories in barriers to medical nutrition therapy was straits due to food limits. Accordingly, Ball, et al. [20] also mentioned about straits the individuals diagnosed T2DM experienced due to food limits.

On the other hand, research findings put forwarded some other themes which would be considered as interesting. All participants mentioned about social pressure. The state of insisting on others' eating and social pressure on eating is peculiar to Turkish culture. Sami, et al. [24] mentioned the success of dietary management requires that the health professionals should have an orientation about the cultural beliefs, thoughts, family, and communal networks of the patients.

Additionally, Participant 8, "When I got divorced from my husband. I started to eat a lot and became so that nobody should see me beautiful and be interested in me as a woman as I live in an environment where women cannot live as they like due to social pressure. I ate food even though I didn't want to eat to become a fat and not a charming woman". As it can be understood from what Participant 8 said, as Participant 8 is a lady who got divorced and lived alone, in order not to attract men's attention and keep herself away from men due to social pressure related to the traditions of the social community where she lived and to show herself powerful and ugly to her social community, she overate. Thus, social community pressure on the individuals with T2DM can be considered as an important barrier in medical nutrition therapy. At the same time, this finding also showed cultural values and norms related to how a woman living alone should protect herself in Turkey. Forouhi, et al. [5] it was emphasized that individual diet recommendations should be adapted in diabetes and personal, cultural and social factors should be taken into consideration.

\section{Overcoming the barriers to achieve medical nutri- tion therapy}

The most remarkable theme in achieving medical nutrition therapy was social support as stated by nine of ten participants. Accordingly, in their study Ridi, et al. [25] mentioned about the importance and the effect of social support in the process in which individuals with T2DM plan and organize what food to eat. Additionally, Bazzazian, [26] and Shao, et al. [27] mentioned about the importance of social support to enable self-management and quality of life in T2DM. These results are parallel with the findings of this study. As seen in re- 
sults, social community had roles both supporting and preventing in health nutrition process. In addition to these outcomes eight out of ten participants mentioned about being moderate instead of restrictions in achieving medical nutrition therapy. Moreover, seven out of ten participants mentioned about self-exploration in achieving medical nutrition therapy. Although the themes of being moderate instead of restrictions and self-exploration are not mentioned much in literature, they could be considered to be effective in achieving medical nutrition therapy.

As this was qualitative study done with ten individuals who applied to Endocrinology and Metabolism Polyclinic and who were diagnosed with T2DM within six months and selected through purposive sampling method based on criteria, the results cannot be generalized to all individuals diagnosed T2DM but limited to participants with whom interviews were done. The results cannot be generalized to all individuals diagnosed T2DM but limited to participants with whom interviews were done.

\section{Conclusion}

In conclusion, in this study medical nutrition therapy process consisted of three sub-themes: Medical nutrition therapy process, barriers to medical nutrition therapy and overcoming the barriers to achieve medical nutrition therapy (Figure 1).

Consistent efforts to improve MNT with patient-centered decision making and support continue to be the foundation of all glycemic therapy. Knowing the patients' experiences with MNT may contribute to providing diet self-management in diabetes. In Turkey nutrition is affected by personality, social traditions, and culture. Therefore, the nutrition of individuals diagnosed T2DM should be taken into consideration from subjective point of view by diabetes nurses. In achieving medical nutrition therapy process individual centered and radical humanist attempts based on individuals' subjective perspectives and opinions instead of attempts based on traditional and paternalist might be planned. In future studies, more comprehensive qualitative or quantitative or mixed methods studies might be conducted in line with the views of T2DM patients on MNT. Individuals' subjective views and experiences about MNT can also guide further researches.

In the treatment of the individuals diagnosed T2DM who have adaptation problems and difficulty in overcoming the barriers in medical nutrition therapy process, individual diabetes nursing instead of group trainings organized in general might be implemented.

\section{Limitation of the Study}

Our study also has some limitations. The study was conducted with volunteers among T2DM patients who came to the Endocrinology and Metabolism Outpatient
Clinic for medical control and were diagnosed in the last 6 months. Therefore, the results of the research can only be generalized to the individuals included in the study.

\section{References}

1. Internation Diabetes Federation (IDF) (2019) Diabetes Atlas. In: Dunia. ( $9^{\text {th }}$ edn).

2. World Health Organization (WHO) (2020) Diabetes.

3. Oğuz A, Çaklili OT, Çalik BT, PURE Investigators (2018) The Prospective Urban Rural Epidemiology (PURE) study: PURE Turkey. Turk Kardiyol Dern Ars 46: 613-623.

4. American Diabetes Association (ADA) (2019) 5. Lifestyle management: Standards of medical care in diabetes-2019. Diabetes Care 42: S46-S60.

5. Forouhi NG, Misra A, Mohan V, Taylor R, Yancy W (2018) Dietary and nutritional approaches for prevention and management of type 2 diabetes. BMJ 361: 2234.

6. Lopez JMS, Katic BJ, Fitz-Randolph M, Jackson RA, Chow W, et al. (2016) Understanding preferences for type 2 diabetes mellitus self-management support through a patient-centered approach: A 2-phase mixed-methods study, BMC Endocr Disord 16: 41.

7. Davies MJ, D'Alessio DA, Fradkin J, Kernan WN, Mathieu C, et al. (2018) Management of hyperglycemia in type 2 diabetes, 2018. A consensus report by the American Diabetes Association (ADA) and the European Association for the Study of Diabetes (EASD). Diabetes Care 41: 26692701.

8. Kempf K, Röhling M, Niedermeier K, Gärtner B, Martin S (2018) Individualized meal replacement therapy improves clinically relevant long-term glycemic control in poorly controlled type 2 diabetes patients. Nutrients 10: 1022.

9. Herman WH (2015) Response to comment on Inzucchi, et al. Management of hyperglycemia in type 2 diabetes, 2015: A patient-centered approach. Update to a position statement of the American diabetes association and the European Association for the study of diabetes. Diabetes Care 38: e143.

10. Habermas J (1987) Knowledge and human interests: A general perspective in knowledge and human interests. Policy, Cambridge.

11. Cohen L, Mannion L, Morrison K (2007) Research methods in education. Routledge, Taylor \& Francis Group.

12. Schwandt TA (2000) Three epistemological stances for qualitative inquiry: Interpretivism, hermeneutics and social constructionism. In: Denzin NK, Lincoln YS, Handbook of qualitative research. Sage, Thousand Oaks, CA, US, 189213.

13. Patton MQ (1990) Qualitative evaluation and research methods. ( $2^{\text {nd }}$ edn), Newbury Park, Sage, CA, US.

14. Robson C (2002) Real world research: A resource for social scientists and practitioners-researchers. ( $2^{\text {nd }}$ edn), Blackwell, Oxford, UK.

15. Langdridge D (2007) Phenomenological psychology: Theory, research and method. Pearson, Harlow, UK.

16. Tong A, Sainsbury P, Craig J (2007) Consolidated criteria for reporting qualitative research (COREQ): A 32-item checklist for interviews and focus groups. Int J Qual Health Care 19: 349-357. 
17. Colaizzi P (1978) Psychological research as a phenomenologist views it. In: Valle RS, King M, Existential Phenomenological Alternatives for Psychology. Open University Press, NewYork.

18. Morrow R, Rodriguez A, King N (2015) Colaizzi's descriptive phenomenological method. The Psychologist 28: 643644.

19. The Society of Endocrinology and Metabolism of Turkey (SEMT) (2019) Clinical practice guideline for diagnosis, treatment and follow-up of diabetes mellitus and its complications - 2019. (12 ${ }^{\text {th }}$ edn), Miki Matbaacilik San, Ankara, Turkey.

20. Ball L, Davmor R, Leveritt M, Desbrow B, Ehrlich C, et al. (2016) Understanding the nutrition care needs of patients newly diagnosed with type 2 diabetes: A need for open communication and patient-focused consultations. Aust $\mathrm{J}$ Prim Health 22: 416-422.

21. Muchiri JW, Gericke GJ, Rheeder P (2019) Adapting a diabetes nutrition education programme for adults with type 2 diabetes from a primary to tertiary healthcare setting. South Afr J Clin Nutr.
22. Masters K (2017) Role Development in Professional Nursing Practice. ( $4^{\text {th }}$ edn), Jones \& Barlett Learning, Burlington, MA.

23. Arkowitz H, Miller WR, Rollnick S (2015) Applications of motivational interviewing. Motivational interviewing in the treatment of psychological problems. ( $2^{\text {nd }}$ edn), The Guilford Press.

24. Sami W, Ansari T, Butt NS, Ab Hamid MR (2017) Effect of diet on type 2 diabetes mellitus: A review. Int $\mathrm{J}$ Health Sci (Qassim) 11: 64-71.

25. Ridi Putra KW, Toonsiri C, Junprasert S (2016) Self-efficacy, psychological stress, family support, and eating behavior on type 2 diabetes mellitus. Belitung Nursing Journal 2: 3-7.

26. Bazzazian S (2017) Biopsychosocial path model of self-management and quality of life in patients with type 2 diabetes. Journal of Bioinformatics and Diabetes 1: 35-44.

27. Shao Y, Liang L, Shi L, Wan C, Yu S (2017) The effect of social support on glycemic control in patients with type 2 diabetes mellitus: The mediating roles of self-efficacy and adherence. J Diabetes Res 2017: 2804178. 